\title{
Téoros
}

Revue de recherche en tourisme

\section{Le Saint-Laurent, magnétique et méconnu}

\section{Normand Cazelais}

Volume 6, numéro 2, juillet 1987

Le Saint-Laurent magnétique

URI : https://id.erudit.org/iderudit/1080498ar

DOI : https://doi.org/10.7202/1080498ar

Aller au sommaire du numéro

Éditeur(s)

Université du Québec à Montréal

ISSN

0712-8657 (imprimé)

1923-2705 (numérique)

Découvrir la revue

Citer ce document

Cazelais, N. (1987). Le Saint-Laurent, magnétique et méconnu. Téoros, 6(2), 2-2. https://doi.org/10.7202/1080498ar d'utilisation que vous pouvez consulter en ligne.

https://apropos.erudit.org/fr/usagers/politique-dutilisation/ 


\title{
Présentation
}

\author{
Le Saint-Laurent, \\ magnétique et méconnu
}

Dira-t-on jamais assez l'importance du Saint-Laurent? Sauronsnous, comme peuple et comme individus, connaître et reconnsitre l'héritage qu'ill nous a legue? Pourrons-nous un jour inventorier et celébrer toutes ses qualites, toutes ses possibilités, toutes ses generosités? Le laisserons-nous vivre et s'epanouir, le laisserons-nous nous aider á nous epanouir ou le laisserons-nous mourir de la mort lente de l'asphyxie et de la négligence?

Poser les termes de la relation entre le Saint-Laurent et le tourisme impose d'explorer les conséquences de telles questions. Le fleuve - puisqu'on l'appelle ainsi, d'une manière si directe qu'elle ne laisse aucun doute sur /'identité du cours d'eau - n'existe pas d'abord pour le plaisir des touristes, fussent-ils d'icl: son role touristique est et sera conséquent de la qualité de l'intégration que nous saurons, en tant que société, lui assurer consciemment et volontairement au sein de nos activites, au sein de notre espace. De notre espace physique et mental.

Indéniablement, le Saint-Laurent attire et fascine. II exerce un magnétisme certain. A preuve, les termes les plus souvent utilisés pour le décrire et l'évoquer référent à la majesté, à la splen. deur, à la grandeur sinon à la démesure. Méme les auteurs des textes qui suivent n'ont pas toujours su y résister... Depuis long. temps, le Saint-Laurent fascine et attire: les écrits de Jacques Cartier et de Champlain en attestent, tout comme les générations de visiteurs qui ont fréquenté ses rives et son cours. Tout comme ceux et celles qui ont peuplé ses abords et utilisé ses ressources.

I/ $\mathrm{y}$ a unanimité: le fleuve est beau. Pus encore, un hymne dit national le qualifie de géant. Le Saint-Laurent est dans l'anti-chambre du mythe.

Et cela se comprend. Le Saint-Laurent est le père, l'ancétre du Québec. Autour de lui, par lui, une collectivite largement livréte à elleméme s'est façonnde un milieu, une culture, une société. Un pays. Dans I'histoire du Quebec, le fleuve fut hieu et lien d'appartenance, d'identification, agent de circulation, $d$ 'organisation et de développement. L"áme du pays.

Nous savons tous /'ampleur du personnage - c'est vraiment un personnage. Pourtant, nous le disons peu: I'Ode au Saint-Laurent de Gatien Lapointe et les toiles des peintres de Charlevoix sont en definitive trop rares. On aurait pu croire le fleuve a la source d'un plus grand nombre d'oeuvres, d'un imaginaire artistique plus imposant.

Le Saint-Laurent, dirait-on, est pris pour acquis...

L'equivalent se retrouve, phis ou moins, dans le monde "merveilleux " du tourisme: le Saint-Laurent exerce son magnétisme mais reste méconnu. Et sous-exploité. $11 \mathrm{y}$ a eu les bateaux blencs de la Canada Steamships; III y a eu les cent ans de villégiature dans Charlevoix; il y a eu les stations de la Cóte du Sud, de Cacouna, de Metis: il y a ou les plages de Contrecoeur et de Lanoraie; il y a eu le Chemin du Roy. $/ Y$ a eu les récits de voyage d'Arthur Buies. II $\mathrm{y}$ a eu, le 18 juillet 1925, la présence du président américant Willam Howard Taft à I'inauguration du galf du Manoir Richelieu. Beaucoup $d^{\prime} W \mathrm{y}$ a ou justement...
Répondre aux questions qu'y a-t-il? et qu'y aura-t-il? s'avére beaucoup plus ardu. Ce fieuve, si "vaste", si "grandiose", si "riche", si "multiple", est a la fois peu lou mal?) connu et faiblement mis en valeur, du moins en fonction de son potentiel. La lecture du monumental ouvrage du géographe Lasserre et du rapport du Projer Saint-Laurent est très révelatrice à ce sujet. Et encore, ces études s intéressaient a l'ensemble des vocations du fleuve et non à sa seule dimension touristique.

Sa dimension touristique est, avouons-le, impressionnante. Telle. ment qu'on ne semble savoir par quel bout commencer. Le SaintLaurent est tout à la fois un attrait linéaire et constitué également d'attraits ponctue/s), un equipement touristique et un axe de trans. port et de circulation. C'est un lieu de nature, de récréation, de repos, d'histoire, d'industrie, de découverte. De patrimoine et d'avenir. Ce fleuve est riviere et mer.

C'est aussile miroir, le reflet de ce que nous sommes et de ce que nous risquons d'étre. Sa santé, par exemple, est en sérieux danger.

Les textes de ce numéro de Téoros ne prétendent pas faire le tour complet de la question de la mise en valeur touristique du SaintLaurent. Toutefois, par la variété de leurs sources et de leur contenu, ils jettent un éclairage qui nous est apparu nécessaire, tant le fleuve a de la difficulté a se défaire de la gangue d'ombre et de laisser-aller qui l'enserre.

Ces textes, écrits par des praticiens, des fonctionnaires, des journalistes et aussi par des universitaires parlent d'histoire, de toponymie, de patrimoine. Is décrivent le fleuve et son histoire. Ils font état egalement de la pollution quil l'assaille, qui met sa santé á rude épreuve et, conséquemment, son potentiel de développement touristique. Is relatent, en puisant dans le vécu, des expériences $d^{\prime}$ exploitation touristique de quelques-unes de ses ressources fla Societé Linnéennel, un essai de mise en valeur de /'une de ses parties (le Parc National Archipel) et les consequences d'un projet mal engagé lie Vieux-Port de Québec).

Ces textes cherchent a préciser un peu plus son potentiel actuel et futur, les juridictions qui s'y exercent. Is tentent en outre de situer dans leur contexte les conditions d'épanouissement touristique du Saint-Laurent: sa vocation touristique au sein de l'ensemble de ses vocations ainsi que la place que fui accordent, dans leur planification territoriale et touristique, les schémas d'aménagement et les plans de développerment régionaux des MRC et des ATR qui touchent à ses berges.

L'avenir touristique du Saint-Laurent est à ce prix: celui de s'accorder aै ses rélles possibilites et de s'integrer a une démarche et à une volonté concertées de mise en valeur. $f$

Normand Cazelais 